\title{
Treating Shock with Spiritual Support
}

\section{Corinna J. Yu, MD, FASA}

Corinna J. Yu, MD, FASA ASA Committee on Young Physicians, and Assistant Professor of Clinical Anesthesia, Indiana University School of Medicine, Indianapolis. She is also a Board Member of the Indiana Society of Anesthesiologists and Women in Anesthesiology.

"Spirituality is a dynamic and intrinsic aspect of humanity through which persons seek ultimate meaning, purpose, and transcendence, and experience relationship to self, family, others, community, society, nature, and the significant or sacred. Spirituality is expressed through beliefs, values, traditions, and practices."

- National Consensus Conference on Creating More Compassionate Systems of Care, 2012 (J Palliat Med 2014;17:642-56)

Shock: inadequate flow to fuel organ systems. When a patient receives the news that they have a terminal diagnosis, they may experience shock. It may be contagious and start a ripple effect to their family members, loved ones, and friends. This shock may not have physical manifestations, but it still cuts off the circulation of hopes, dreams, and aspirations that fuel our mental, emotional, and spiritual systems. This is especially prevalent during the coronavirus pandemic. I was shocked to learn about cytokine storms wreaking havoc on otherwise healthy

This is the author's manuscript of the work published in final edited form as:

Yu, C. J. (2020). Treating Shock with Spiritual Support. ASA Monitor, 84(11), 32-32.

https://doi.org/10.1097/01.ASM.0000722152.50292.43 
patients, and I scrambled to update my own advance directive. Patients were caught unsuspecting, quarantined from their families and loved ones, and left stranded in the hospital to die alone. At best, a health care worker video-conferenced with the family to say goodbye (N Engl J Med 2020;382:e88). At worst, the patient took their dying breath among strangers scrambling to repurpose resources to save other lives. Upon death, they were remembered in empty funeral homes with physical distancing, covered faces, or virtual hugs. Amid this tragedy, physicians may be the very last people to have physical contact with the dying. Physicians should take a spiritual history, set expectations with patients and families, and provide spiritual support to prevent and treat spiritual shock.

\section{Take a spiritual history}

In the same way that the medical profession began training students in the 1970 s to take a history to acknowledge the sexual lives of our patients, we need to train ourselves to take a spiritual history (Anesthesiology 2004;101:1055). In a 2018 study with 165 third-year medical students, educators trained students to address patients' spiritual needs during surgery/anesthesiology clerkships (MedEdPORTAL 2018;14:10784). Screening tools such as FICA (Faith, Importance and Influence, Community, Address/Action in Care) and HOPE (Hope, Organized religion, Personal spirituality and Practices, Effects on medical care and Endof-life issues) are also available (Am Fam Physician 2012;86:546-50; J Palliat Med 2000;3:12937; Am Fam Physician 2001;63:81-9). In fact, The Joint Commission requires a spiritual assessment in the medical record, although it does not specify what it looks like (Standards FAQs: Medical Record - Spiritual Assessment). We need to address our patients' spiritual health 
and allow them to share their spiritual needs. This task is the responsibility of all physicians ( $\mathrm{J}$ Pain Symptom Manage 2018;55:1035-40). It allows us to make better decisions and consult hospital chaplains when necessary to provide specialized spiritual support to the patient and their family.

\section{Set expectations}

I interviewed Joshua Schreiner, MDiv, who worked as a hospital chaplain and has been working as a home hospice chaplain since the coronavirus pandemic (J. Schreiner, personal communication, August 4,2020). According to Schreiner, one of the most important things that physicians can do to help their patients is to set expectations. The sooner we can identify and communicate that a patient requires palliative or hospice care, the sooner accommodations can be made to avoid shock. The Perioperative Surgical Home (PSH) encourages anesthesiologists to embrace their role as leaders in palliative care (Anesth Analg 2018;127:284-8). Dr. Perry Fine writes, "With an aging population and $>40$ million anesthetics performed every year in the United States alone, an increasingly large proportion of patients present themselves to the PSH with advanced illness, significant symptom burdens, and a wide variety of social needs, circumstances, goals, and values" (Anesth Analg 2018;127:12-4). As anesthesiologists, we may have the first opportunity to recognize the medical complexity and challenge of upcoming surgery and the possibility or likelihood of negative outcomes. We have a responsibility to share that knowledge and help set expectations for our patients and their families. 


\section{Communicate with family}

Good communication requires acknowledging a patient in their environment and communicating with their family. We care for multiple people when we take care of a pregnant patient and her baby or try to educate parents to stop smoking for their children's sake.

Similarly, we need to take care of our patients in the context of their families, according to the patients' wishes. For example, caring for families during the coronavirus pandemic may include careful communication about resource scarcity and changing care plans toward palliative or hospice care (CMAJ 2020;192:E400-4). Good communication can help the family unit traverse the Kubler-Ross stages of grief (On Death and Dying 1970), from denial, anger, bargaining, and depression, and help them reach acceptance. It helps the family unit in their shared decisionmaking, especially if the patient becomes incapacitated and did not leave an advance directive. It can prevent the symptoms of shock that cascade into family fights and finger-pointing that compound the stress of the dying.

\section{Provide spiritual support}

One way to provide spiritual support to our patients is to stop and listen. Schreiner suggests that an effective end-of-life counseling session takes about 30 minutes. "Everyone has a spirituality, how they get their hope and meaning," says Schreiner. In 2017, the Pew Research Center stated that $81 \%$ of Americans are religious or spiritual (Pew Research Center, September 2017). Schreiner uses reflective listening and open-ended questions to understand how the patient is feeling and allow them to share stories about their life. Reminiscing can bring peace to the 
patient and be therapeutic to family members who can listen and be healed through the conversation. As he encouraged a patient to share stories of his life, the patient's daughter began to cry happy tears and said, "That was the best gift anybody could ever give me!"

We have a privilege and a responsibility to care for both the physical and spiritual systems. We need to address our patient's spiritual health through their spiritual history, set appropriate expectations, and if clinical duties allow, stop and listen. As we continue to navigate uncharted waters in the coronavirus pandemic, physicians play a critical role in treating spiritual shock. During the physical wreckage that occurs at the end of life, we need to salvage spiritual support for our patients and their families. 